\title{
New perspectives in biomonitoring liver function by means of serum bile acids: experimental and hypothetical biochemical basis
}

\author{
G Franco
}

\begin{abstract}
The functional activity of the liver and the variety of its responses to injury makes the choice of appropriate tests of function a difficult task. Because of the highly efficient uptake of bile acids by the normal hepatocyte, the determination of serum bile acid (SBA) concentration has been proposed as a test to detect early changes of liver function not associated with cytotoxicity. Several biomonitoring studies have been carried out on subjects occupationally exposed to hepatotoxic substances, by evaluating SBAs as indicators of early liver dysfunction. Even though these studies are not exactly comparable because of the different protocols adopted, most of them show a significant increase in SBA concentrations among the exposed subjects compared with unexposed controls. Furthermore, higher prevalences of subjects with abnormal SBA concentrations occur in those exposed to mixtures of organic solvents. Increased SBA concentrations among the subjects exposed to various xenobiotics have been explained by assuming a change in function of hepatocytes. As regards the nature of the mechanisms involved in the increase in SBA concentrations, recent experimental observations pointed out that some chlorinated aliphatics were able to inhibit cell membrane ATPases and alter cytosolic calcium homeostasis. The lack of any relation, however, between exposure and SBA concentrations remains an important point to clarify and at present prevents the use of measurement of SBA concentrations as an index of effect.
\end{abstract}

The central role of the liver in the biotransformation of xenobiotics makes it a target organ for

Dipartimento di Medicina Preventiva, Occupazionale e di Comunità dell'Università di Pavia, via Severino Boezio, 24, I-27100 Pavia, Italy G Franco occupational and non-occupational xenobiotics. Biomonitoring liver function of subjects occupationally exposed to hepatoxic substances is a difficult task because the present tests do not have the required specificity and sensitivity necessary to explore liver function in such subjects. More sensitive and specific indices to detect effects on liver as a consequence of exposure to hepatotoxic xenobiotics are needed. ${ }^{1}$ Even though the measurement of serum bile acids (SBAs) was initially considered a research model, this test seems to be both sensitive in showing early liver dysfunction and specific because high concentrations of SBAs are an expression of hepatobiliary defects. Recent investigations into the measurement of SBA concentrations as a test may be considered, broadly, as three groups-namely, epidemiological studies and experimental studies in vivo and in vitro-and are discussed under these headings.

\section{Epidemiological studies}

In the period 1984-90 several studies of behaviour of SBAs in groups of workers occupationally exposed to various chemicals were undertaken, six of which appeared in scientific publications and 10 of which were presented at congresses of occupational medicine. ${ }^{2-17}$

METHODS AND POPULATION GROUPS

Total SBAs were measured by enzymatic methods, ${ }^{691113-15}$ the conjugated derivatives of cholic acid and chenodeoxycholic acid with taurine and glycine by immunoenzymatic methods or by radioimmunoassay, ${ }^{2-5810-12}$ and the single acids and derivatives by high pressure liquid chromatography. ${ }^{1617}$

All the study populations (except ${ }^{4}$ ) comprised men. The mean age of the subjects varied from $30^{12}$ to $49^{4}$. As regards intake of ethanol, the maximum quantity of ethanol allowed for the inclusion of subjects in the study differed according to local lifestyle and varied from $50 \mathrm{~g}$ to $90 \mathrm{~g}$ a day. ${ }^{6-81013} \mathrm{In}$ some studies subjects were included regardless of their intake of ethanol. ${ }^{24511121617}$ Hepatic diseases and consumption of drugs were motives for the exclusion of subjects from the studies. Some other 
selection criteria included availability of liver biopsy, ${ }^{5}$ the presence of other diseases, ${ }^{78}$ exposure to contrast media ${ }^{8}$ and blood transfusion. ${ }^{15}$ In general, these criteria were also employed in selecting control groups. Sometimes the results were compared with reference values for the general population. ${ }^{318}$

\section{OCCUPATIONAL EXPOSURE}

Large differences exist among the studies regarding type and degree of exposure to chemicals. The studies considered exposure to more or less complex mixtures of chemicals as follows: styrene, ${ }^{2-479}$ aromatic solvent mixtures, ${ }^{31013}$ complex organic solvent mixtures, ${ }^{6111214}$ hydrocarbon mixture, ${ }^{8}$ chlorinated derivatives of aliphatic hydrocarbonsnamely, vinyl chloride, ${ }^{3515}$ polyvinyl chloride, ${ }^{3}$ perchloroethylene, and methylene chloride (unpublished data)-and other chemicals-namely, dimethylformamide, ${ }^{13}$ pentachlorophenol, ${ }^{6}$ and rubber factory fumes. ${ }^{17}$

Environmental concentrations of chemicals are reported in various ways. Mean values and range $^{2-469-111314}$ or maximum values are given, ${ }^{318}$ in some studies exposure levels are obtained from exposure indices, ${ }^{716}$ and in others no data are presented. ${ }^{3581217}$ In general, exposure levels are lower than the limit values prescribed by the American Conference of Governmental Industrial Hygienists (ACGIH). Only three studies consider workers exposed at concentrations higher than ACGIH limit values. These are for solvent mixtures ${ }^{614}$ and styrene. ${ }^{4}$ Some studies obtained exposure level from the measurement of index of dose (mandelic acid for styrene exposure, ${ }^{9}$ and pentachlorophenol, ${ }^{16}$ and perchloroethylene (unpublished data)) for the exposure to these chemicals. In other studies exposure was evaluated by measurement of the compound itself in biological media-for example, toluene and xylene concentrations in blood and urine, ${ }^{10}$ and 1,1,1,-trichloroethane, ${ }^{11}$ perchloroethylene, and methylene chloride in urine (unpublished data).

\section{BEHAVIOUR OF SERUM BILE ACIDS}

The table shows the results. Styrene is the most studied single chemical. Results are contradictory and only in some instances measurement of SBA concentration is able to discriminate exposed from unexposed subjects. ${ }^{239}$ Also in exposure to solvent mixtures some differences exist in the behaviour of SBA. Exposure to aromatic hydrocarbons, however, causes, to a relatively constant degree, an increased prevalence of subjects showing higher SBA concentrations. ${ }^{31013}$ Several studies consider exposure to complex organic solvent mixtures containing aromatic and aliphatic hydrocarbons and their chlorinated derivatives and the results are not comparable, due to lack of exposure data. Increased concentrations of $\mathrm{SBA}^{6}$ and of cholic acid (CA) and chenodeoxycholic acid (CDCA) were found in one study $^{12}$ whereas no changes were detected in other studies. ${ }^{114}$

For exposure to chlorinated derivatives of hydrocarbons and particularly to vinyl chloride, some studies agree in the finding of increased CA and CDCA concentrations ${ }^{35}$ although a more recent study fails to confirm this observation. ${ }^{15}$ Methylene chloride and perchloroethylene exposure at around

Behaviour of SBAs in subjects occupationally exposed to various chemicals

\begin{tabular}{|c|c|c|}
\hline \multirow[b]{2}{*}{ Exposure chemical } & \multicolumn{2}{|l|}{ Exposure level } \\
\hline & $(\%$ Of $T L V)$ & $S B A$ \\
\hline 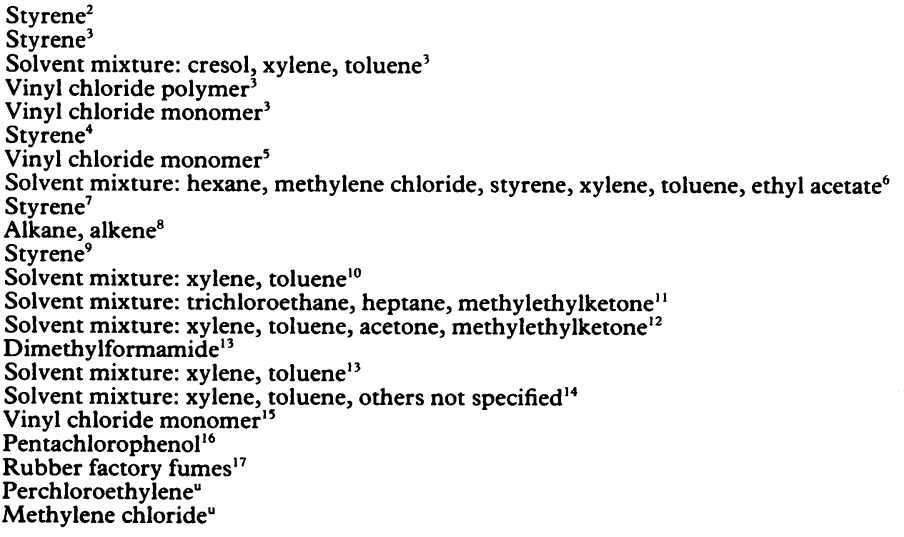 & $\begin{array}{rl} & 20-94 \\
<71 & 40-70 \\
& \overline{20} \\
< & 56-205 \\
\overline{177}-1039 & < \\
< & 50 \\
<\overline{6} \\
<100 \\
<30 \\
\frac{100}{100} \\
<100 \\
<240 \\
<\overline{28} \\
<\overline{16} \\
<114\end{array}$ & $\begin{array}{l}+ \\
+ \\
+ \\
\text { NS } \\
+ \\
\text { NS } \\
+ \\
+ \\
\text { NS } \\
\text { NS } \\
+ \\
+ \\
\text { NS } \\
+ \\
+ \\
+ \\
\text { NS } \\
\text { NS } \\
+ \\
\text { NS } \\
\text { NS } \\
\text { NS }\end{array}$ \\
\hline
\end{tabular}

+ Indicates a statistically significant increase in mean value or in prevalence among the exposed subjects compared with controls. NS = Non-significant. TLV is as prescribed by ACGIH. Superscripts are reference numbers; ${ }^{\prime}=$ unpublished data. 
the ACGIH limit values did not cause significant changes in SBA concentrations (unpublished data).

Some studies evaluated the dose response relation between environmental, blood, or urinary chemical concentration and SBA concentration. As exposure indices, toluene and xylene in blood and urine, ${ }^{10}$ pentachlorophenol in blood and urine, ${ }^{16}$ and methylene chloride and perchloroethylene concentrations in urine (unpublished data) were evaluated. No significant relations between these indices and SBA concentrations were found.

\section{BEHAVIOUR OF SBA IN RELATION TO OTHER LABORATORY PARAMETERS}

Further evaluation considered the behaviour of traditional liver function tests (most measurements of aminotransferase, $\gamma$-glutamyl-transpeptidase, and alkaline phosphatase activities, and bilirubin concentrations), which were studied together with changes in SBA concentrations. Several studies showed no increase in mean values of the parameters measured, in particular, aminotransferases, and no increase in the prevalence of exposed subjects with abnormal values compared with controls. ${ }^{2691316}$ Therefore, the increase in SBA concentrations precedes that of the indices of cytolysis and thus could represent an index of early hepatic dysfunction. Other studies reported the alteration of at least one parameter together with increased SBA concentration ${ }^{312}$ whereas the remaining studies showed the alteration of at least one parameter not associated with increase in SBA concentration. ${ }^{7813-15}$ These last data do not support the hypothesis that change in SBA concentration could indicate early liver dysfunction.

\section{Experimental in vivo studies}

In rats exposed to trichloroethylene (via inhalation and intraperitoneal injection) a dose dependent increase in serum concentrations of cholic acid and chenodeoxycholic acid conjugated with glycine and taurine derivatives was found. ${ }^{18}$ Furthermore, after treatment with trichloroethylene, serum activities of alkaline phosphatase and sorbitol dehydrogenase were not changed and that of alkaline aminotransferase was raised only at the highest dose, confirming that changes in liver function evaluated by means of SBA concentrations are seen earlier and in the absence of any cytolytic alteration. Similarly increased SBA concentrations occurred after treatment with $\alpha$-naphthylisothiocyanate, an established compound used as a model hepatotoxin for studying changes in bile flux. These results suggest that the hepatobiliary disturbance could be common for both trichloroethylene and $\alpha$-naphthylisothiocyanate even though no mechanism responsible was identified. The relation between dose and increased SBA concentration is clearly proved in the intraperitoneally administered trichloroethylene experiment (whereas the dose dependency is less clear in the experiment carried out by inhalation). This result is not consistent with the data in man, and it is necessary to stress the difference between experimental and occupational exposure to chemicals. In fact, no relation was found in subjects occupationally exposed to various chlorinated aliphatic hydrocarbons (unpublished results), xylene, and toluene. ${ }^{10}$

\section{Experimental in vitro studies}

Progress has recently been made in the understanding of normal bile flux mechanisms by the use of isolated hepatocytes and hepatocyte plasma membranes. Each change in the transport mechanisms that control the absorption, transport, and secretion phases could modify the biliary flux that is followed by the increase in SBA concentration. Several mechanisms able to induce changes in bile flux were identified: (1) $\mathrm{Na}^{+} \mathrm{K}^{+}$ATPase inhibition, (2) increase in the permeability of the paracellular pathway, (3) cytoskeleton changes, and (4) increase in permeability of smooth endoplasmic reticulum to calcium. Of these steps, most information is available regarding the carrier mediated uptake across the sinusoidal membrane of the hepatocyte. ${ }^{19}$

Hepatocellular transport mechanisms were recently investigated in isolated hepatocyte suspensions exposed to 1,1,1-trichloroethane and tetrachloroethylene. The exposure to these chemicals, in doses that did not cause cytolysis and ultrastructural changes in hepatocytes, resulted in the inhibition of uptake of taurocholic acid in a dose dependent manner together with the concurrent inhibition of the ouabain and 2-aminoisobutyric acid transport mechanisms.$^{20}$ Furthermore, the exposure of hepatocyte plasma membranes to these chemicals resulted in a reversible decrease of ATPase activities, which is known to be an essential mechanism responsible for the almost complete extraction, by means of a $\mathrm{Na}^{+}$dependent mechanism of cotransport, of SBA from sinusoidal blood. ${ }^{19}$

These results, although obtained from in vitro experiments, could provide the biochemical and cellular basis necessary to explain the increased SBA concentrations seen in occupationally exposed subjects. In fact, they showed that the spillover of SBA with the succeeding increase of SBA concentrations in the systemic circulation could be explained as a consequence of the impairment of uptake mechanisms. Moreover, impairment of SBA uptake represents a sensible biological event that occurs earlier than the increase in parameters of cytolysis. These results are consistent with studies in man and could explain the reason for the more widely altered SBA concentrations compared with other function test indices. They could, however, also justify those studies that failed to find any change in SBA concentrations among exposed subjects. In fact the 
inhibition of ATPase due to exposure to halogenated compounds was shown to be reversible. ${ }^{21}$ The negative studies in man could have failed to detect a change in SBA concentrations, not because the effect (the alteration of the SBA uptake mechanism) had not occurred, but simply because, being reversible, it was no longer present.

Among the other mechanisms able to induce changes in bile flux ((1) increase in the permeability of the paracellular pathway, (2) changes in the cytoskeleton, (3) increase in permeability of smooth endoplasmic reticulum to calcium) the first two, even though proved for a variety of drugs, cannot be invoked for occupational chemicals at present. The third, however, was seen to be an important factor in determining cholestasis. In particular, carbon tetrachloride and 1,1-dichloroethylene were effective in inhibiting the calcium pump in the endoplasmic reticulum with an increase of cytosolic calcium leading to the impairment of a number of intracellular transport processes. ${ }^{22}$

\section{Conclusions}

The studies carried out in the last six years lead to no definitive conclusions about the possible use of SBA as an index of effect predictive of health impairment resulting from exposure. Measurement of SBA concentration is sensitive because the concentration increases at a low degree of exposure to many chemicals and this could be regarded as a favourable characteristic. A correct application of indices of effect, however, requires a knowledge of both the biochemical mechanism of toxic action of chemicals and the cellular sites at which alteration is responsible for the effects. Recent advances have been made in the knowledge of these aspects. In particular, chlorinated aliphatics were shown to cause an impairment of uptake of SBA and to alter the calcium pump in the endoplasmic reticulum of the hepatocyte. Both these changes in the transport mechanisms controlling the absorption (hepatocyte SBA uptake) and the transport (regulated by the calcium pump in the endoplasmic reticulum) phases could modify biliary flux, which, in turn is followed by an increase in SBA concentration.

Although measurement of SBA is characterised by a high sensitivity, it shows a noticeable lack of specificity, as many chemicals share the same biochemical and cellular mechanisms responsible for its increase. Therefore, even though some experimental studies support the possibility that SBA concentration may be adopted as an index of effect, ${ }^{18}{ }^{20}$ at present its use for biomonitoring liver function in subjects exposed to chemicals cannot be recommended.

Further studies are required to clarify the different behaviours of SBA in subjects exposed to the same kind of chemicals (particularly, aromatic hydro- carbons and chlorinated aliphatic and aromatic hydrocarbons). Moreover, because of the contradictory results in the dose effect relation for studies in man and animal and cellular studies, it is necessary to study further the relation between behaviour of SBA and exposure (above all at low levels). In fact, it is necessary for the validation of the use of a biological change as an index of effect to establish a relation between exposure and the biological change itself.

1 Anonymous. Industrial agents and the liver. Lancet 1982; ii: $1081-2$.

2 Edling C, Tagesson C. Raised serum bile acid concentrations after occupational exposure to styrene: a possible sign of hepatotoxicity? Br J Ind Med 1984;41:257-9.

3 Vihko $R$, Vihko $P$, Mäentausta $O$, Pakarinen $A$, Jänne $O$, Yrjanheikki E. Assessment of early hepatotoxicity. In: Aitio A, Riihimaki W, Vainio $\mathrm{H}$, eds. Biological monitoring and surveillance of workers exposed to chemicals. Washington: Hemisphere Publ Corp, 1984:309-13.

4 Härkönen H, Lehtniemi A, Aitio A. Styrene exposure and the liver. Scand J Work Environ Health 1984;10:59-61.

5 Liss GM, Greenberg RA, Tamburro $\mathrm{CH}$. Use of serum bile acids in the identification of vinyl chloride hepatotoxicity. $\mathrm{Am}$ J Med 1985;78:68-76.

6 Franco G, Fonte R, Tempini G, Candura F. Serum bile acid concentration as a liver function test in workers occupationally exposed to organic solvents. Int Arch Occup Environ Health 1986;58:157-64.

7 Bergamaschi E, Mutti A, Ferrari M, et al. Liver damage and enzyme induction tests among styrene exposed workers. In: Foà V, Emmett EA, Maroni M, Colombi A, eds. Occupational and environmental chemical hazards. Chichester: Ellis Horwood Ltd, 1987:159-63.

8 Germanò D, Barbaro M, Pendino GM, et al. Elevazione della concentrazione sierica della colilglicina dopo pasto colecistocinetico in lavoratori esposti cronicamente a vapori di benzine. In: Atti Soth Congresso Nazionale Società Italiana Medicina del lavoro e Iqiene Industriale, Roma, 21-24 October 1987; I:245-50.

9 Goggi E, Cazzaniga A, Caspani A, Pasqualone B. Indici di funzionalità epatica in lavoratori professionalmente esposti a basse concentrazioni di stirene. In: Atti 50th Congr Naz Soc It Med Lav Ig Ind, Roma, 21-24 October 1987;I:265-8.

10 Franco G, Santagostino G, Lorena M, Imbriani M. Conjugated serum bile acid concentrations in workers exposed to low doses of toluene and xylene. $\mathrm{Br} J$ Ind Med 1989;46:141-2.

11 Riboldi L, Buratti M, Colombi A, Imbriani M, Ghittori S Valutazione della funzione epatica in soggetti esposti cronicamente a basse dosi di 1.1.1-tricloroetano, eptano tecnico e metiletilchetone. In: Atti 52nd Congr Naz Soc It Med Lav Ig Ind, Palermo 28 September-1 October 1989:1185-90.

12 Allegri F, La Paglia G, Cacciato R, et al. Gli acidi biliari primari nella valutazione dell'esposizione a solventi. In: Atti 52nd Congr Naz Soc It Med Lav Ig Ind, Palermo, 28 September-1 October 1989:255-63.

13 Fiorito A, Negro C, Zanin T, Bovenzi M. Comportamento degli acidi biliari sierici in lavoratori esposti ad epatotossici. In: $A t t i$ 52nd Congr Naz Soc It Med Lav Ig Ind, Palermo, 28 September-1 October 1989:249-53.

14 Chen JD, Wang JD, Jang JP, Chen YY. Biochemical alterations of the liver and exposure to mixtures of solvents among pain workers. 23rd International Congress on Occupational Health, Montreal, 22-28 September 1990:282.

$15 \mathrm{Wu} Y Q$, Wang JD. Abnormal liver function among the employees of PVC polymerization plants. 23rd International Congress on Occupational Health, Montreal, 22-28 September 1990:299.

16 Colosio C, Maroni M, Colombi A, et al. Profilo degli acidi biliari serici in soggetti cronicamente esposti a pentaclorofenolo. In: Atti 53rd Congr Naz Soc It Med Lav Ig Ind, Stresa, 10-13 October 1990:1207-11.

17 Riboldi L, Buratti M, Pellegrino O, Caravelli G, Colombi A. Foà V. Porfirinuria in addetti alla produzione di manufatti in gomma. In: Atti 53rd Congr Naz Soc It Med Lav Ig Ind, Stresa, 10-13 October 1990:1213-8. 
18 Wang G, Stacey NH. Elevation of individual serum bile acids on exposure to trichloroethylene or a-naphthylisothiocyanate. Toxicol Appl Pharmacol 1990;105:209-15.

19 Frimmer M, Ziegler K. The transport of bile acids in liver cells. Biochim Biophys Acta 1988;947:75-99.

20 Kukongviriyapan V, Kukongviriyapan U, Stacey NH. Interference with hepatocellular substrate uptake by 1,1,1-trichloroethane and tetrachloroethylene. Toxicol Appl Pharmacol 1990;102:80-90.

21 Rufeger U, Frimmer M. Inhibition of polyhalogenated hydrocarbons (PHHC) of ATPases in plasma membranes of parenchymal liver cells. Naunyn-Schmiedeberg's Archives of Pharmacology 1976;193:187-90.

22 Moore L, Schoenberg DR, Long RM. Impact of halogenated compounds on calcium homeostasis in hepatocytes. Environ Health Perspect 1990;84:149-53.

Accepted 17 December 1990 